\title{
A Cost/Benefit Framework for Consumer Product Safety Standards
}

\author{
Cart O. Muehlhause
}

National Engineering Laboratory, National Bureau of Standards, Washington, DC 20234

June 26, 1978

\begin{abstract}
The effect of a mandated consumer product safety standard on the net public benefit is expressed in terms of the difference between two well characterized market states (pre- and post-standard), each of which is assumed to be in static equilibrium. The analysis is facilitated by treating the post-standard state as one which can be "derived" from the pre-standard state by 1) expanding the production cost and demand functions around their initial market values and 2) introducing modifications in the production cost function required for compliance with the standard.

A gain in net benefit would imply that promulgation of the standard is favorable; however, a variety of uncertainties are encountered in estimating the incremental changes in production, demand, compliance, and regulatory costs. These are discussed, some of the simpler situations which may prevail are disclosed, and the sources of expertise required to effect the analysis are identified.

The detailed portion of the analysis undertaken in this paper is one which attempts to derive a market factor such that when it is multiplied by the basic increment in manufacturing cost necessary to comply with the standard yields the loss in net benefit due to the market system. The results are then applied to a case involving the manufacturing and retailing of upholstered furniture, which industries may be subject to a certain fire prevention standard.
\end{abstract}

Key words: Consumer; cost-benefit; fire hazard; market; regulation safety standards; upholstered furniture.

\section{Introduction}

It is generally recognized and in fact expected from the language $[1]^{1}$ of the Consumer Product Safety Act that an analysis of the costs and benefits associated with a proposed consumer product safety standard be undertaken in support of that standard. It is the purpose of this paper to set out a reasonable and generally applicable cost benefit framework into which the various principal costs and benefits can be exhibited and related to one another. In addition, it is also the purpose of this paper to apply the general method of analysis to the case of a proposed standard for upholstered furniture, which standard is designed to avoid the initiation of fires by smoldering cigarettes.

Several studies of this specific case have already been undertaken $[2,3]$ and a significant new attempt to estimate the avoided damages has recently been completed by the National Bureau of Standards [4]. This paper is in support of the latter work and also undertakes the task of providing an overall framework for analysis as well as to estimate specifically the effect of the market system per se (producers, retailers, and consumers) on the cost to society of promulgating the standard.

\section{General Concepts}

The problem to be addressed is one in which some industry, i.e., group of firms, has been producing a product which consumers find useful but for which there exists a significant hazard in that use. In this paper, the hazard is assumed to be one which is either ill perceived or totally ignored by consumers, thereby giving rise to damage costs which lie outside the market system of producers and consumers. Such costs or "externalities" must be regarded as detrimental of the public interest, in that society incurs more damage cost in using the product in question than it would otherwise be willing to bear if only there had been a mechanism available for proper accounting of those costs and of incorporating improved features of product safety into the market system. Such a mechanism can be provided by the regulator, e.g., the Consumer Product Safety Commission (CPSC). With knowledge of the cause and effect of the hazard as well as of the feasibility of

\footnotetext{
${ }^{1}$ Figures in brackets indicate literature references at the end of this paper.
} 
industry to redesign that product at "reasonable" cost, the regulator may set a safety standard for that product with which producers must now comply. How well this can be done and indeed whether in a given instance the public interest is served will depend upon how well the regulator can anticipate the costs and benefits which are involved. These include the damage costs avoided by the standard as well as the production and other costs incurred by the industry. These are difficult quantities to estimate, even by "experts."

In between the industrial engineering system which produces the safer product and the consumers who use it lies the regulated market system. Just how this system functions is also uncertain. It is dynamic rather than static and should be treated with econometric methods that allow forecasting. In this paper, however, the simpler approach of "comparative statics" is undertaken. This is one in which two static equilibrium states of the market are envisioned. The first of these constitutes the pre-standard condition and the second the poststandard condition. To realize the latter enough time is presumed to have elapsed that the market has once more reached a "steady" state.

The above model does not relieve the need to account for certain important time-dependent parameters, a most notable one being the durability or mean lifetime of the product in question. The avoided external damage costs are spread out over this time interval and must therefore be discounted back to present value, in order to be put on the same basis as the purchase price and other terms in the accounting system.

Another time conditioned problem is the one of how industry might schedule a series of changes or accommodations in production to meet the requirements of the standard. In this paper only changes which are initially evident and which may also be regarded as only "perturbing" the original production cost function are considered.

Still another problem of considerable significance for performing the analysis indicated has to do with the "market structure" of the industry in question. This is conditioned by whether the market is competitive or not, and of the relationship among other market factors as well. For example, it may be important whether or not retailing is included under the same management as manufacturing. These and some other factors will be specifically dealt with as they are encountered below.

The effect of the standard on cost avoidance is of course at the heart of the safety problem and the belief that the standard could be effective provides the motive for assessing production and market costs such as have been mentioned above. In this paper the cost avoidance will only be indicated in a formal way and not further disected. Special methods, entirely ad hoc to those discussed in this paper, are required for their assessment. For example, the method of decision analysis applied to plausible hazard scenarios may be appropriate [4].

The model is intended to be simple, but at the same time useful as a framework for exhibiting the principle components of consumer product safety in a way which it is hoped can aid responsible public interest decision making.

\section{Organization}

The paper proceeds by first establishing a number of general concepts and principles, the most important of which is the metric for measuring how well off society can be regarded to be as a function of the value it places upon the product in question, of the cost to produce those products, and of the risk of injury to consumers stemming from their interaction with those same products. This measure termed the net public benefit, $\eta$, or benefit net of all cost, dependent as it is on the quantities cited, will exhibit a different value in the post as compared with the pre-standard state. Accordingly, its evaluation permits comparison of these two states and of the determination of whether society was made better off or not by promulgation of the standard.

Having established the proper metric, the role of the regulator is discussed and, more particularly, the means by which he sets the standard and effects compliance. New cost terms are identified for the poststandard state which contribute to the net public benefit. Some costs have increased, as for example the costs required to produce the safer product. Other costs have decreased, as for example the damage costs.

This paper not only takes as given these latter avoided costs, but also the basic increment in $\operatorname{cost}, \bar{C}$, to the industry required to accommodate the standard, i.e., to produce a safer product. The present work thus seeks to incorporate all of the costs and benefits into one proper accounting scheme, which scheme includes the effects of the market per se, i.e., of the effect of $\bar{C}$ on price and demand and how this in turn affects the net public benefit. 
With the ability to construct the proper net benefit measure one is then in a position to critique a proposed standard from the point of view of the regulator, and to analyze whether or not the proposed standard is likely to effect a gain in net public benefit. This is carried out under two different models of presumed behavior or decision making on the part of the producers.

The first model considered is the classic marginal cost type model, or one which presumes the producer is able to fine-tune his production process to optimal conditions (albeit utilizing only a few simple parameters). This model results in a reasonably highly efficient allocation of resources and a correspondingly low "market factor," MF, which factor is such that when it is multiplied by the incremental manufacturing cost required to accommodate the standard, yields the loss to society of bearing the costs of the improved product.

The second model considered is termed a "gross decision" model, and is one in which the producer is presumed able to arrange his production process so as to realize a certain target profit fraction on sales. In both cases actual operating data are utilized to set the profits and other operating ratios at values actually realized in practice.

Having fully defined the two models of producer-retailer-consumer behavior, four quantities are calculated for each case. Statistical operating data from the manufacturing and retailing industries, along with a price elasticity for home furniture derived from other sources permits these calculations.

The four quantities calculated are: the "market factor," MF; the fractional change in sales volume, $\Delta q / q$; the change in manufactured furniture price relative to the manufacturing cost increment, $\Delta P_{m} / \bar{C}$; and the change in retail price relative to the same manufacturing cost increment, $\Delta P_{s} / \bar{C}$.

Finally, some estimates of $\bar{C}$ are taken from the work of others [4] at NBS in order to indicate to the reader approximately how the case for the proposed furniture standard comes out; however, the reader must pursue this with the forthcoming fuller work on the subject if he is to appreciate the additional complicating details of the case.

\section{Net Public Benefit}

Before proceeding with considerations of the market per se it is important to establish a measure of how well off society is regarded to be in its consumption of a product wherein there exists a hazard in use. This measure is termed the "net public benefit," $\eta$, and is the benefit net of all cost. In the following expression of this quantity some simplifications have been made, e.g., in basic acceptance and in the use of suitable average unit damage costs [5]; however, the same end results could have been obtained with somewhat greater generality.

Regard the demand schedule to be decomposed into a distribution such that the differential contribution to the demand, i.e., consumption rate, is given by:

$$
d q\left(V_{p}\right)=\frac{d q}{d V_{p}} d V_{p}
$$

where $V_{p}$ is an effective value assignment to the utility of the product independent of price and risk assessment. Regard too that the consumer perceives some risk in the use of that product for which he requires a compensation [6], $\bar{V}_{r}{ }^{\prime}$, this being a suitable average value. If the market price be $P_{m}$, then the demand, $q_{m}$, is given by:

$$
q_{m}=\int_{0}^{q_{m}} d q \equiv \int_{\infty}^{P_{m}+\bar{V}_{r}^{\prime}} \frac{d q}{d V_{p}} \cdot d V_{p}
$$

This is to say that unless $V_{p}$ exceeds $P_{m}$ by at least $\bar{V}_{r}{ }^{\prime}$ the demand falls to zero.

Though the perceived value of the risk governs demand, the net public benefit is also governed by the actual losses that require compensation, $\bar{V}_{r}$. The net benefit, $\eta$, is therefore given by:

$$
\eta=\int_{\infty}^{P_{m}+\bar{V}_{r}{ }^{\prime}}\left(V_{p}-\bar{V}_{r}(\omega)\right) \frac{d q}{d V_{p}} \cdot d V_{p}-C_{p}(q, \omega)
$$


where $C_{p}(q, \omega)$ is the production cost to yield " $q$ " products per unit time with safety feature $\omega$. This is to say that the existence of $\omega$ gives rise to both the perceived, $\bar{V}_{r}^{\prime}$, and actual, $\bar{V}_{r}$, risk compensations. In this formalism safety is regarded to increase with increasing $\omega$.

If it were possible (socially) to optimize $\eta$ (subject to the demand constraint), the following conditions would prevail:

$$
\begin{aligned}
& \frac{\partial C_{p}}{\partial q_{m}}+\left(\bar{V}_{r}-\bar{V}_{r}^{\prime}\right)=P_{m} \\
& \frac{\partial C_{p}}{\partial \omega}+q_{m} \frac{\partial \bar{V}_{r}}{\partial \omega}=0
\end{aligned}
$$

which conditions along with the demand constraint would determine $P_{m}, q_{m}$, and $\omega$ (see appendix A).

The first of these relationships states that the price should be set at the marginal cost to society of production plus unexpected damage. Note that if $\bar{V}_{r}=\bar{V}_{r}^{\prime}$, the classic riskless marginal cost condition prevails.

The second of these relationships states that the engineered safety feature, $\omega$, should be so chosen that the marginal cost of engineered safety is just compensated by the real cost of avoided damages.

Note too, that in the special case wherein $\bar{V}_{r}^{\prime}=0$, i.e., the consumer ignores safety, the net public benefit can be written:

$$
\eta=\int_{\infty}^{P_{m}} V_{p} \frac{d q}{d V_{p}} d V_{p}-C_{p}(q, \omega) \|-q_{m} \bar{V}_{r}(\omega)
$$

or for greater simplicity in terminology:

$$
\eta=\int_{0}^{q_{m}} P d q-C_{p}(q, \omega) \quad \|-q_{m} \bar{C}_{e}(\omega)
$$

where $q=q(P)$, the demand schedule, and $\bar{C}_{e}(\omega)$ is the unit cost or damage lying outside the market system. This is the notation which will be employed in the remainder of this paper, terms not accountable by the producer/consumer market being shown beyond the "double bar."

\section{Perfect Competition}

It is now of interest to examine how an industry operating under conditions of perfect competition and perfect knowledge would respond to the case just outlined. Consider some adequately large number of competitive firms each producing apparently identical products, but wherein the safety feature can be different. Consider too that, although consumers ignore safety in their demand for the product, the industry could still be held partly liable for the personal damages caused by its products. For the $i$ th firm:

$$
C_{p i}=C_{p i}\left(q_{i}, \omega_{i}\right) \quad \text { and } \quad C_{l i}=q_{i} \bar{C}_{l}\left(\omega_{i}\right)
$$

where $C_{p i}$ and $C_{l i}$ are the production and liability costs respectively faced by the $i$ th firm, $\bar{C}_{l i}$ being the unit liability cost. $q_{i}$ is the production rate of the $i$ th firm, and $\omega_{i}$ the safety feature of the $i$ th firms product that correlates with damages. As was stated earlier all costs spread out in time must be discounted back to present value.

If the $i$ th firm then seeks to optimize its net revenue, $\pi_{i}$, where:

$$
\pi_{i}=P_{m} q_{i}-C_{p i}\left(q_{i}, \omega_{i}\right)-q_{i} \bar{C}_{l}\left(\omega_{i}\right)
$$

then, under an industry wide price, $P_{m}$, this would lead to: 


$$
\begin{array}{ll}
\frac{\partial C_{p i}}{\partial \omega_{i}}+\bar{C}_{l}\left(\omega_{i}\right)=P_{m} & \\
\frac{\partial C_{p i}}{\partial \omega}+q_{i} \frac{\partial \bar{C}_{l}}{\partial \omega_{i}}=0 & \text { for all } i
\end{array}
$$

and which along with:

$$
\sum_{i} q_{i}=q_{m}=q\left(P_{m}\right)
$$

yields all of the $q_{i}, \omega_{i}$, and $P_{m}$.

The above set of equations could also have been derived from optimizing the following expression:

$$
\int_{0}^{q_{m}} P d q-\sum_{i} C_{p i}\left(q_{i}, \omega_{i}\right)-\sum_{i} q_{i} \bar{C}_{l}\left(\omega_{i}\right)
$$

subject to the demand constraint, and as shown in appendix B.

This will be recognized as a partial net public benefit expression such as cited in (1), but wherein only those costs faced by the producer are accountable, i.e., costs up to the "double bar." The initial (i.e., prestandard) complete net public benefit $\eta_{1}$ is therefore given by:

$$
\eta_{1}=\int_{0}^{q}{ }_{1}^{1} P d q-\sum_{i} C_{p i}\left(q_{i}, \omega_{i}\right)-\sum_{i} q_{i} \bar{C}_{l}\left(\omega_{i}\right) \quad \|-\sum_{i} q_{i} \bar{C}_{e}\left(\omega_{i}\right)
$$

and under conditions of perfect knowledge could be presumed to be subject to the conditions cited above which optimizes $\eta_{1}$ up through the internal costs. Thus, though perfect competition and perfect knowledge of the market would allow society to approach optimum conditions (e.g., as might be contrasted with noncompetitive conditions) it is not of itself sufficient to guarantee maximum economic efficiency. To achieve the latter some portion of the external costs would need to be "internalized," i.e., held accountable to producers.

In passing it is also worthy to note that the net public benefit, e.g., $\eta_{1}$ above, can also be regarded as the sum of the net gains of the parties in the exchange. For the case above these consist of consumer and producer surpluses. For consumers the gain is the difference between the benefit integral and $P_{m} q_{m}$ plus external damage costs. For producers the surplus or profit is the difference between $P_{m} q_{m}$ and the production and liability costs. The exchange term $P_{m} q_{m}$ thus cancels out in summing the surpluses. The point is raised here so as to alert the reader to certain situations, e.g., as in credit buying, in which this cancellation is not complete, but can give rise to a residual term as shown in appendix $\mathrm{C}$.

\section{Regulatory Action}

If now a regulator enters the scene his job may be regarded as one which is to set a standard and effect some complicance penalty so as to "force" the producers to raise the safety feature to some higher level, this level being so chosen as to reduce the external damage cost significantly more than it raises production and other costs. If such can be achieved, the net public benefit as defined above will have increased. In principle, the regulator would wish to optimize $\eta$, but in practice would still be considered successful if, by promulgating the standard, he would increase $\eta$ over its initial (pre-standard) value.

The method of gaining compliance can take on a variety of forms, e.g., through various sampling and inspection schemes [7]. All such schemes have associated with them testing and administrative costs, both for the producer as well as for the regulator - all of this being in addition to the increased production costs which must also be incurred to produce the safer products.

In effect the regulator creates an artifice or penalty cost function with which the producer must comply. He cannot actually make the producer directly accountable to the external damage costs per se, but only to a new 
cost which he, the regulator, imposes. The shape of that compliance cost function (including administrative costs) may appear as shown in figure 1 . Shown there is a steep compliance function, $\bar{C}_{c i}$, designed to force the producer to operate beyond his initial value at $\sim \omega_{1}$ to a region $\sim \omega_{0}$, the value sought or anticipated by the regulator. In principle this value would approximately optimize $\eta_{1}$; however, there are too many complications and uncertainties to expect literal optimization [7].

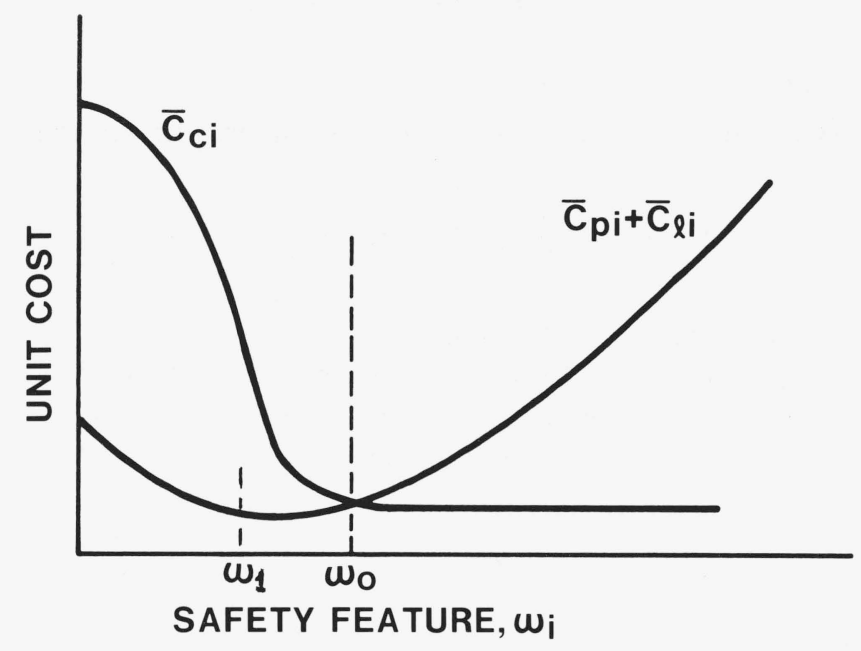

Figure 1. Unit production, liability, and compliance costs as a function of safety feature for ith firm

In any case a perfectly competitive and knowledgeable industry would now act to optimize:

$$
\int_{0}^{q_{m}} P d q-\sum_{i} C_{p i}\left(q_{i}, \omega_{i}\right)-\sum_{i} q_{i} \bar{C}_{l}\left(\omega_{i}\right)-\sum_{i} C_{c i}\left(q_{i}, \omega_{i}\right)
$$

subject to the same demand constraint as was previously considered to hold. Thus for the $i$ th firm under the new (post-standard) conditions:

$$
\begin{array}{ll}
\frac{\partial C_{p i}}{\partial q_{i}}+\bar{C}_{l}\left(\omega_{i}\right)+\frac{\partial C_{c i}}{\partial q_{i}}=P_{m} & \\
\frac{\partial C_{p i}}{\partial \omega_{i}}+q_{i} \frac{\partial \bar{C}_{l i}}{\partial \omega_{i}}+\frac{\partial C_{c i}}{\partial \omega_{i}}=0 & \text { for all } i
\end{array}
$$

which along with the demand constraint now determines a new set of $q_{i}, \omega_{i}$, and $P_{m}$.

Whereas the liability costs may possibly be represented as proportional to the number of products sold multiplied by some constant unit cost (a function of $\omega_{i}$ ), the compliance costs are likely to consist at least of a fixed and variable part, wherein the variable is dependent upon $q_{i}$ as well as the state of $\omega_{i}$. No attempt will be made in this paper to specify the exact shape of these functions. The same comment holds for the regulatory administrative $\operatorname{cost} C_{r i}$ utilized below.

Associated with this "final state" is a final net public benefit, $\eta_{2}$ : 
$\eta_{2}=\int_{0}^{q_{m}} P d q-\sum_{i} C_{p i}\left(q_{i}, \omega_{i}\right)-\sum_{i} q_{i} \bar{C}_{l}\left(\omega_{i}\right)-\sum_{i} C_{c i}\left(q_{i}, \omega_{i}\right) \quad \|-\sum_{i} q_{i} \bar{C}_{e}\left(\omega_{i}\right)-\sum_{i} C_{r i}\left(q_{i}, \omega_{i}\right)$

where again the terms beyond the "double bar" represent the residual external damage as well as the administrative cost to the regulator required to check compliance for the $i$ th firm.

Again it would be expected that external damage costs could be represented as some constant average unit cost (a function of $\omega_{i}$ ) multiplied by the number of products sold. The regulatory administrative costs however would consist of at least fixed and variable parts, as was stated previously for the administrative costs (testing, rejection, etc.) faced by the producer.

As was also indicated earlier, the public interest would be served if $\Delta \eta$ the change in net benefit, $\eta_{2}-\eta_{1}$, were positive. Accordingly, one is interested in:

$\Delta \eta=\int_{q_{1}}^{q_{2}} P d q-\sum_{i} \Delta C_{p i}-\sum_{i} \Delta q_{i} \bar{C}_{l}\left(\omega_{i}\right) \quad-\sum_{i} C_{c i}\left(q_{i}, \omega_{i}\right) \|-\sum_{i} \Delta_{q_{i}} \bar{C}_{e}\left(\omega_{i}\right)-\sum_{i} C_{r i}\left(q_{i}, \omega_{i}\right)$

where $q_{1}$ and $q_{2}$ are the quantities produced in the first and second states respectively, and $\Delta q_{i}=q_{2 i}-q_{1 i}$.

For state $1, q_{1}=q\left(P_{1}\right)$ and:

$$
\begin{array}{ll}
\left(\frac{\partial C_{p i}}{\partial q_{i}}\right)_{1}+\bar{C}_{l i}=P_{1} & \\
\left(\frac{\partial C_{p i}}{\partial \omega_{i}}\right)_{1}+q_{i} \frac{\partial \bar{C}_{l}}{\partial \omega_{i}}=0 & \text { for all } i
\end{array}
$$

For state $2, q_{2}=q\left(P_{2}\right)$ and:

$$
\begin{array}{ll}
\left(\frac{\partial C_{p i}}{\partial q_{i}}\right)_{2}+\bar{C}_{l i}+\frac{\partial C_{c i}}{\partial q_{i}}=P_{2} & \\
\left(\frac{\partial C_{p i}}{\partial \omega_{i}}\right)_{2}+q_{i} \frac{\partial \bar{C}_{l}}{\partial \dot{\omega}_{i}}+\frac{\partial C_{c i}}{\partial \omega_{i}}=0 & \text { for all } i
\end{array}
$$

from which, in principle, one may calculate $\Delta \eta$.

\section{Perfect Versus Non-Perfect Conditions}

It is important first to note that if the change from state 1 to state 2 can be regarded as infinitesimal, then to first order $\Delta \eta$ is given by:

$$
\begin{aligned}
& \Delta \eta=P d q-\sum_{i}\left(\frac{\partial C_{p i}}{\partial q_{i}} d q_{i}\right.\left.+\frac{\partial C_{p i}}{\partial \omega_{i}} d \omega_{i}\right) \\
&-\sum_{i}\left(\bar{C}_{l} d q_{i}+q_{i} \frac{\partial \bar{C}_{l}}{\partial \omega_{i}} d \omega_{i}\right)-\sum_{i}\left(\frac{\partial C_{c i}}{\partial q_{i}} d q_{i}+\frac{\partial C_{c i}}{\partial \omega_{i}} d \omega_{i}\right) \\
& \|-\sum_{i} \Delta q_{i} \bar{C}_{e}\left(\omega_{i}\right)-\sum_{i} C_{r i}\left(q_{i}, \omega_{i}\right)
\end{aligned}
$$


Employing (5) it is evident that the sum of terms up to the double bar is zero. This follows simply from the assumption of optimization by industry of its net revenue in consideration of the actual costs which the industry faces. Thus for there to exist a gain in net public benefit:

$$
-\Delta C_{e}-\Delta C_{r}>0
$$

or since $C_{e}$, the total (i.e., as opposed to unit) cost $<0$, the absolute value of avoided damages $\left|\Delta C_{e}\right|$ must exceed the total cost required to regulate the standard. That is:

$$
\left|\Delta \mathrm{C}_{e}\right|>\Delta C_{r}
$$

if an infinitesimal standard is to be net beneficial.

It is next worthy to note that if noncompetitive conditions prevail the incremental internal terms do not cancel to first order. For example, in a pure monopoly it can be shown that a first order term:

$$
-P_{1} \Delta q / e
$$

arises where $e$ is the price elasticity given by:

$$
e=\frac{P}{q}\left(\frac{\partial q}{\partial P}\right)
$$

evaluated at $\left(q_{1}, P_{1}\right)$ in this instance. Thus, since both $e$ and $\Delta q$ are negative, this term further detracts from a possible gain in net public benefit.

Finally, it is particularly important to note also at this point that though producers and retailers may operate under competitive conditions, they do so with imperfect knowledge. In general, suppliers may not be able to operate on marginal decision rules such as have been posed above; rather they may need to operate on types of gross rules (based on experienced operating ratios) and of course they may also experience unanticipated outcomes. This failure to anticipate ultimate prices and to manage the supply side of the market perfectly gives rise to additional costs. An analysis utilizing gross rather than marginal decision rules will be developed in a later section. It could constitute the preferred analytical approach. Prior to that the full implication of marginal rule decision making will be explored, and later compared with the gross rule results.

\section{Marginal Analysis-Conceptual}

For more substantial changes due to the imposition of the standard, the demand and production cost functions need to be expanded around the original pre-standard market conditions. Whereas under the assumption of constant price elasticity over the limited range from state 1 to state 2 , this may readily be accomplished for the demand function, it is not so evident for the production function. Specific insight into production and systems engineering for the particular response to the standard is required. This is tantamount to recognizing that $C_{p}\left(q_{i}, \omega_{i}\right)$ is not known, i.e., as a mathematical function over wide ranges of the variables. At best $C_{p}$ may be known as a function of $q_{i}$ in the neighborhood of $q_{i 1}$ to $q_{i 2}$. For changes in $\omega_{i}$ however, the industrial engineer would need to estimate costs for particular ways of accommodating the improved safety requirement.

Perhaps the simplest situation is one in which the manufacturer need only incorporate more costly materials into his product, which material changes do not alter his production and assembly process. This case may, for example, be approximated by the home upholstered furniture industry (SIC-2512), which industry may be required by the Consumer Product Safety Commission to meet improved fire resistant upholstered furniture standards (a significant cause of fires being due to ignition of the upholstery by cigarettes). An adequate solution to the proposed standard may be to utilize modified fabrics and padding which are more resistant to ignition or which have been treated with ignition suppressant material [3, 4]. Though these materials are in turn supplied by the textile manufacturers (at some higher cost) responsibility for producing the higher performing product falls primarily to the furniture manufacturer. 
The manufacturer thus experiences an additional production cost linear in the quantity produced. Let this be designated by $\bar{C}_{\omega}$. Although $\omega_{i}$ and therefore $\bar{C}_{\omega}$ may be somewhat maneuverable by each firm, it is likely to be set within narrow limits near some anticipated value, say $\omega_{0}$. The unit external damage cost, $\bar{C}_{e}$, and the ignition resistant material cost, $\bar{C}_{\omega}$, may appear approximately as shown in figure 2 .

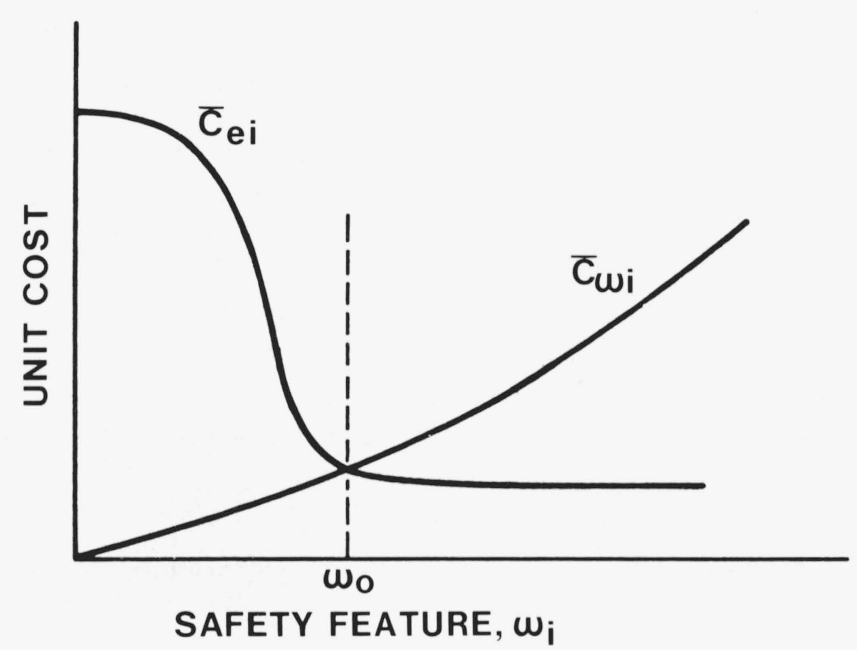

Figure 2. Unit external damage cost and incremental unit production cost as a function of safety feature for the ith firm.

Thus the total new cost which the $i$ th producer faces consists of:

$$
q_{i} \bar{C}_{\omega_{0}}+C_{c i}\left(q_{i}, \omega_{0}\right)
$$

moreover, if the compliance term $C_{c i}$ can be broken into fixed and variable costs, the total new cost can also be represented this way. Hopefully, the administrative portion of these new costs will be small $(<$ ten percent); however, the fixed portion alone may sometimes be a serious matter for compliance by small producers. In what follows the fixed portion of $C_{c i}$ will be ignored and the incremental manufacturing cost will be indicated simply as $\bar{C}$. Such a situation would constitute perhaps the simplest type of change or cost increment in the production segment of the market. Other more complex types of changes to accommodate $\omega_{0}$ could alter the original assembly process itself and in a non-linear way.

Having conceptualized the case as discussed above, two additional oversimplifications of this conceptualization need be noted. Both have to do with perturbations on the supplier of materials to the manufacturer that are a consequence of the standard. For the industry in question these would be on the textile producer. The first perturbation has to do with whether the standard will so alter the demand for certain fabrics and materials that the supply of these materials will be significantly altered. It is not believed that this is the case, although some shift in the prices of these materials could take place. The extent to which this may occur is sufficiently tenuous that the effect was not included in the analysis in an interactive way, i.e., through prescribed couplings such as will be presented below between the furniture manufacturer and the retailer. The second perturbation has to do with the imposition of the standard directly on the textile manufacturer. The standard calls for the classification of fabrics according to certain flammability tests which would then qualify them for certain types of furniture construction. Thus the textile manufacturer as well as the furniture manufacturer 
must comply with certain aspects of the standard. Accordingly, the fabric supplier also experiences certain administrative and testing costs required for compliance. However, these costs are much less severe for the textile manufacturer than for the furniture manufacturer and, as with the other perturbation mentioned, are sufficiently tenuous as to preclude their incorporation in the analysis as interactive elements. Thus the analysis which will be undertaken includes some estimate of this cost; however, it does so by including it only in the estimation of the aforementioned $\bar{C}$. Whereas the magnitude of $\bar{C}$ affects the outcome of the analysis, it does so only as a parameter and not as a variable conditioned by the furniture manufacturing and retailing market.

To analyze this kind of basic case in adequate detail it is necessary to distinguish those "production" costs which depend upon the higher price material input from those which do not. It is necessary therefore to reconsider the basic relationships.

In both the pre-standard and the post-standard states there are costs (few percent) which are proportional to the value of the inventory and final selling price. For example, if the salesman receives a commission this would constitute such a cost. There are also revenues (few percent) which are proportional to the selling price. Credit buying, for example, constitutes such. It may, of course, also be important to account for whether retailing is conducted under the same management as manufacturing. In the upholstered household furniture industry these two functions come under separate management, i.e., are carried out by independent firms. In what follows it shall be assumed that both industries are competitive and, therefore, a universal market price, $P_{m}$, for identical products is achieved at the interface between manufacturer and retailer, and a second universal price, $P_{s}$, is realized for the consumer. The furniture industries also appear free of liability costs; accordingly, these latter cost terms will be dropped from the analysis.

For the case of marginal type fine-tuned decision making, the $j$ th retailer would be expected to optimize his net revenue, $\pi_{j}$, which is composed approximately as follows:

$$
\pi_{j}=P_{s} q_{j}-C_{s j}\left(q_{j}\right)-\left(1+f_{s}\right) P_{m} q_{j}-g_{s} P_{s} q_{j}
$$

In this expression $C_{s j}$ is considered to represent the cost of retailing not associated with capital inventory and sales commissions, $f_{s}$ represents the financial charges on the inventory, and $g_{s}$ represents the commission paid on sales. The effect of credit buying does not appear in this expression, as it has been assumed (see appendix C) that the time payments made by the consumer exactly compensate the seller for the costs that arise from having to receive delayed payments. Optimization of $\pi_{j}$ yields:

$$
\frac{\partial C_{s j}}{\partial_{q i}}+\left(1+f_{s}\right) P_{m}=\left(1-g_{s}\right) P_{s}
$$

Similarly, the $i$ th manufacturer would be expected to optimize $\pi_{i}$, given by:

$$
\pi_{i}=P_{m} q_{i}-C_{p i}\left(q_{i}\right)-\left(1+f_{m}\right) V_{m} q_{i}-g_{m} P_{m} q_{i}
$$

Again $f_{m}$ represents the financial charge on the inventory whose unit cost is $V_{m}$, and $g_{m}$ represents the commission paid on sales. Optimization of $\pi_{i}$ yields:

$$
\frac{\partial C_{p i}}{\partial q_{i}}+\left(1+f_{m}\right) V_{m}=\left(1-g_{m}\right) P_{m}
$$

Considering the $f$ and $g$ factors to be fixed and the material cost, $V_{m}$, to be known, the $j$-set of retailing equations and the $i$-set of manufacturing equations taken together along with:

$$
q_{m}=\sum_{i} q_{i}=\sum_{j} q_{j}=q_{s}=q\left(P_{s}\right)
$$

determines all of the $q_{i}, q_{j}$, as well as $P_{m}$ and $P_{s}$.

From a yet broader perspective the apparently "fixed" factors $(f, g)$ could be shown to arise from a more extensive optimization procedure. For example, the practice of paying a commission rather than a salary to 
salesmen presumably derives from the increased incentive and therefore increased sales which the salesman realizes when working on a commission. One might regard that the demand is a function of $g_{s}$ as well as $P_{s}$; however, the details which would lead to the particular trade-off near $g_{s} \sim$ five percent are not well known. Consequently, such factors are regarded as fixed with respect to the analysis, i.e., to be constant for both preand post-standard states.

Proceeding with the analysis, each of the two net public benefit expressions may be regarded as the sum of the three surpluses: consumer, retailer, and manufacturer, in addition to the costs lying outside the market system.

$$
\begin{aligned}
\eta_{1}= & \int_{\infty}^{\left(1+f_{c}\right) P_{1}} P d q-\left(1+f_{c}\right) P_{s 1 q 1} \\
& +P_{s 1} q_{1}-\sum_{j} C_{s j}\left(q_{j}\right)-\left(1+f_{s}\right) P_{m 1} q_{1}-q_{s} P_{s 1} q_{1} \\
& +P_{m 1} q_{1}-\sum_{i} C_{p i}\left(q_{i}\right)-\left(1+f_{m}\right) V_{m} q_{1}-g_{m} P_{m 1} q_{1} \quad \|-\bar{C}_{e 1} q_{1} \\
\eta_{2}= & \int_{\infty}^{\left(1+f_{c}\right) P_{2}} P d q-\left(1+f_{c}\right) P_{s 2} q_{2} \\
& +P_{s 2} q_{2}-\sum_{j} C_{s j}\left(q_{j}\right)-\left(1+f_{s}\right) P_{m 2} q_{2}-g_{s} P_{s 2} q_{2} \\
& +P_{m 2} q_{2}-\sum_{i} C_{p i}\left(q_{i}\right)-\left(1+f_{m}\right)\left(V_{m}+\bar{C}_{m}\right) q_{2}-\bar{C}_{l} q_{2} \\
& -g_{m} P_{m 2} q_{2} \|-\bar{C}_{e 2} q_{2}-\bar{C}_{r} q_{2}
\end{aligned}
$$

where $f_{c}$ is a factor which stems from credit buying, a discussion of which is given in appendix C, and where $\bar{C}_{m}$ is the increment in material cost and $\bar{C}_{l} *$ the increment in labor cost to comply with the standard. For simplicity $\bar{C}_{l}$ is assumed to affect only the linear portion of the production cost function.

The change $\left(\eta_{2}-\eta_{1}\right)$ in net benefit thus becomes (see appendix $C$ ):

$$
\begin{aligned}
\Delta \eta= & \left(1+f_{c}\right) \int_{q_{1}}^{q_{2}} P d q-\left(f_{c}+g_{s}\right)\left(P_{s 2} q_{2}-P_{s 1} q_{1}\right) \\
& -\left(f_{s}+g_{m}\right)\left(P_{m 2} q_{2}-P_{m 1} q_{1}\right)-\left(1+f_{m}\right) V_{m} \Delta q \\
& -\left(\sum_{j 2} C_{s j}\left(q_{j}\right)-\sum_{j 1} C_{s j}\left(q_{j}\right)\right)-\left(\sum_{i 2} C_{p i}\left(q_{i}\right)-\sum_{i 1} C_{p i}\left(q_{i}\right)\right) \\
& -\bar{C}_{l q_{2}}-\left(1+f_{m}\right) \bar{C} q_{2}+\left(\bar{C}_{e 1} q_{1}-\bar{C}_{e 2} q_{2}-\bar{C}_{r} q_{2}\right)
\end{aligned}
$$

* Note "l" subscript stands for labor, not liability as it previously did, but which terms were dropped from the analysis. 
In addition, using (8) and (10):

$$
\begin{aligned}
& \left(\frac{\partial C_{s j}}{\partial q_{j}}\right)_{1}=\left(1-g_{s}\right) P_{s 1}-\left(1+f_{s}\right) P_{m 1} \\
& \left(\frac{\partial C_{s j}}{\partial q_{j}}\right)_{2}=\left(1-g_{s}\right) P_{s 2}-\left(1+f_{s}\right) P_{m 2} \\
& \left(\frac{\partial C_{p i}}{\partial q_{i}}\right)_{1}=\left(1-g_{m}\right) P_{m 1}-\left(1+f_{m}\right) V_{m} \\
& \left(\frac{\partial C_{p i}}{\partial q_{i}}\right)_{2}=\left(1-g_{m}\right) P_{m 2}-\left(1+f_{m}\right)\left(V_{m}+\bar{C}_{m}\right)-\bar{C}_{l}
\end{aligned}
$$

For the marginal case to provide a solution, the two supply cost functions, $C_{p i}$ and $C_{s j}$ must consist of at least three terms in $q_{i}$ and $q_{j}$, respectively; e.g., a fixed, linear, and quadratic term. The quadratic, in particular, is required to limit the production of each firm, i.e., to provide a rising marginal cost at high supply rates. It is the marginal conditions which allow ready computation of the various supply quantities and their differences (between states 1 and 2). Thus if:

$$
\begin{aligned}
C_{p i} & =C_{0 i}+\alpha_{i} q_{i}+\beta_{i} q_{i}^{2} \text { and } \\
C_{s j} & =C_{0 j}+\alpha_{j} q_{j}+\beta_{j} q_{j}^{2} \text { then } \\
2 \beta_{i} \Delta q_{i} & =\left(1-g_{m}\right) \Delta P_{m}-\left(1+f_{m}\right) \bar{C}_{m}-\bar{C}_{l} \\
2 \beta_{j} \Delta q_{j} & =\left(1-g_{s}\right) \Delta P_{s}-\left(1+f_{s}\right) \Delta P_{m}
\end{aligned}
$$

from which:

$$
\begin{aligned}
\Delta q_{m} & =\sum_{i} \Delta q_{i}=\frac{1}{2}\left[\left(1-g_{m}\right) \Delta P_{m}-\bar{C}_{l}-\left(1+f_{m}\right) \bar{C}_{m}\right] \sum_{i} \beta_{i}{ }^{-1} \\
\Delta q_{s} & =\sum_{j} \Delta q_{j}=\frac{1}{2}\left[\left(1-g_{s}\right) \Delta P_{s}-\left(1+f_{s}\right) \Delta P_{m}\right] \sum_{j} \beta_{j}^{-1}
\end{aligned}
$$

Thus if there is no net change in inventory, then to first order:

$$
\Delta q=\Delta q_{m}=\Delta q_{s} \simeq e q_{1} \frac{\Delta P_{s}}{P_{s 1}}
$$

which relations yield $\Delta q, \Delta P_{m}$, and $\Delta P_{s}$ as shown in appendix E.

In appendix D it is readily shown that to second order:

$$
\int_{q_{1}}^{q_{2}} P d q=P_{s 1} \Delta q+\frac{1}{2} \Delta P_{s} \Delta q
$$

which, when combined with the expressions for $\Delta P_{s}, \Delta P_{m}$, and $\Delta q$, permits the calculation of $\Delta \eta$, given the parameters invoked. This is undertaken below.

First however it should be noted that each of the supply functions, $C_{p i}$, and $C_{\mathrm{s} j}$ may be expanded to higher order. For example: 


$$
C_{p i 2}=C_{p i 1}+\left(\frac{\partial C_{p i}}{\partial q_{i}}\right) \Delta q_{i}+\frac{1}{2}\left(\frac{\partial^{2} C_{p i}}{\partial q_{i}^{2}}\right) \Delta q_{i}{ }^{2}+\ldots
$$

and also:

$$
\left(\frac{\partial C_{p i}}{\partial q_{i}}\right)_{2}=\left(\frac{\partial C_{p i}}{\partial q_{i}}\right)_{1}+\left(\frac{\partial^{2} C_{p i}}{\partial q_{i}^{2}}\right)_{1} \Delta q_{i}+\ldots
$$

Thus to second order:

$$
\Delta C_{p i}=\left(\frac{\partial C_{p i}}{\partial q_{i}}\right)_{1} \Delta q_{i}+\frac{1}{2}\left[\left(\frac{\partial C_{p i}}{\partial q_{i}}\right)_{2}-\left(\frac{\partial C_{p i}}{\partial q_{i}}\right)_{1}\right]_{1} \Delta q_{i}=\frac{\Delta q_{i}}{2}\left[\left(\frac{\partial C_{p i}}{\partial q_{i}}\right)_{1}+\left(\frac{\partial C_{p i}}{\partial q_{i}}\right)_{2}\right]
$$

and similarly for $C_{s j}$. Thus:

$$
\begin{aligned}
& \left.\sum_{i} \Delta C_{p i}=\frac{\Delta q}{2}\left[\left(1-g_{m}\right)\left(P_{m 1}+P_{m 2}\right)-\left(1+f_{m}\right)\left(2 V_{m}+\bar{C}_{m}\right)-\bar{C}_{l}\right)\right] \\
& \sum_{j} \Delta C_{s j}=\frac{\Delta q}{2}\left[\left(1-g_{s}\right)\left(P_{s 1}+P_{s 2}\right)-\left(1+f_{s}\right)\left(P_{m 1}+P_{m 2}\right)\right]
\end{aligned}
$$

Returning now to $\Delta \eta$ :

$$
\begin{aligned}
\Delta \eta= & \left(1+f_{c}\right)\left(P_{s 1} \Delta q+\frac{1}{2} \Delta P_{s} \Delta q\right)-\left(f_{c}+g_{s}\right)\left(P_{s 2} q_{2}-P_{s 1} q_{1}\right) \\
& -\left(f_{s}+g_{m}\right)\left(P_{m 2} q_{2}-P_{m 1} q_{1}\right)-\left(1+f_{m}\right) V_{m} \Delta q \\
& -\frac{\Delta q}{2}\left[\left(1-g_{s}\right)\left(P_{s 1}+P_{s 2}\right)-\left(1+f_{s}\right)\left(P_{m 1}+P_{m 2}\right)\right] \\
& -\frac{\Delta q}{2}\left[\left(1-g_{m}\right)\left(P_{m 1}+P_{m 2}\right)-\bar{C}_{l}-\left(1+f_{m}\right)\left(2 V_{m}+\bar{C}_{m}\right)\right] \\
& -\left(1+f_{m}\right) \bar{C}_{q_{2}}+\left[\Delta C_{e}\right] \text { where: } \\
& {\left[\Delta C_{e}\right] \equiv\left[\bar{C}_{e 1} q_{1}-\left(\bar{C}_{e 2}+\bar{C}_{r}\right) q_{2}\right] }
\end{aligned}
$$

Cancellation and combination leads to:

$$
\Delta \eta=-q_{1}\left(1+\frac{\Delta q}{2 q_{1}}\right)\left[\left(f_{c}+g_{s}\right) \Delta P_{s}+\left(f_{s}+g_{m}\right) \Delta P_{m}+\bar{C}_{l}+\left(1+f_{m}\right) \bar{C}_{m}\right]+\left[\Delta C_{e}\right]
$$


Since both $\Delta P_{s}$ and $\Delta P_{m}$ will be shown to be proportional to $\bar{C}$ it is useful to construct from this expression for $\Delta \eta$ a market factor, MF, such that when it is multiplied by $q_{1} \bar{C}$ yields the loss in net public benefit due to the production-consumption process. Accordingly:

$$
\begin{aligned}
M F & \equiv-\frac{\Delta \eta-\left[\Delta C_{e}\right]}{q_{1} \bar{C}}=\left(1+\frac{\Delta q}{2 q_{1}}\right)\left[1+f_{m}+\left(f_{c}+g_{s}\right) \frac{\Delta P_{s}}{\bar{C}}+\left(f_{s}+g_{m}\right) \frac{\Delta P_{m}}{\bar{C}}\right] \text { where } \\
\bar{C} & =\bar{C}_{m}+\bar{C}_{l} /\left(1+f_{m}\right)
\end{aligned}
$$

which to first order can be written:

$$
M F=1+f_{m}+\left(f_{c}+g_{s}\right) \frac{\Delta P_{s}}{\bar{C}}+\left(f_{s}+g_{m}\right) \frac{\Delta P_{m}}{\bar{C}}+\frac{\Delta q}{2 q_{1}}
$$

To evaluate this expression the results of appendix $\mathrm{E}$ need be utilized. There it is shown:

$$
\frac{\Delta P_{s}}{\bar{C}}=\gamma \quad \frac{\Delta q}{q_{1}}=\gamma e \frac{\bar{C}}{P_{s 1}}
$$

and

$$
\frac{\Delta P_{m}}{\bar{C}}=\frac{\left(1+f_{m}\right)\left(\sum_{j} \beta_{j}^{-1}\right)^{-1}+\left(1-g_{s}\right)\left(\sum_{i} \beta_{i}^{-1}\right)^{-1} \cdot \gamma}{\left(1-g_{m}\right)\left(\sum_{j} \beta_{j}^{-1}\right)^{-1}+\left(1+f_{s}\right)\left(\sum_{i} \beta_{i}^{-1}\right)^{-1}}
$$

where

$$
\gamma=\frac{\left(1+f_{s}\right)\left(1+f_{m}\right)}{\left(1-g_{m}\right)\left(1-g_{s}\right)-k}
$$

and

$$
k=\frac{2 e q_{1}}{P_{s 1}}\left[\left(1-g_{m}\right)\left(\sum_{j} \beta_{j}^{-1}\right)^{-1}+\left(1+f_{s}\right)\left(\sum_{i} \beta_{i}^{-1}\right)^{-1}\right]
$$

In order to actually calculate the market factor and the other quantities indicated, one must utilize actual operating data as may be found, for example, from reports issued by the manufacturing [8] and retailing [9] associations for the industries in question. In addition, of course, one must utilize some appropriate value for the price elasticity, $e$. The latter may be found from an analysis of dynamic consumption such as is performed annually on the United States economy [10]. With respect to the former, three "operating ratios" in each industry need to be invoked. These have been chosen as $p$, the profit, measured as a fraction of sales; $F$, the fixed costs, again measured as a fraction of sales; and the ratio of material cost to selling price. These last ratios are $V_{m} / P_{m 1}$ and $P_{m 1} / P_{s 1}$ for manufacturing and retailing respectively. It must also be understood that the operating ratios are for the initial or prestandard state only. This is not simply for the reason that, as in the case of the standard for the furniture industry this is the only data available, but because these ratios are not fixed (i.e., must be allowed to vary) in going from the pre-standard to the post-standard state.

For manufacturing:

$$
\pi_{i}=p_{m 1} P_{m 1} q_{i 1}=P_{m 1} q_{i 1}-F_{m 1} q_{i 1}-\alpha_{i} q_{i 1}-\beta_{i} q_{i 1}^{2}-\left(1+f_{m}\right) \frac{V_{m}}{P_{m 1}} P_{m 1} q_{i 1}-g_{m} P_{m 1} q_{i 1}
$$




$$
\text { or } \quad \alpha_{i}+\beta_{i} q_{i 1}=P_{m 1}\left[1-p_{m 1}-F_{m 1}-\left(1+f_{m}\right) \frac{V_{m}}{P_{m 1}}-g_{m}\right]
$$

However, from the optimizing marginal condition:

$$
\alpha_{i}+2 \beta_{i} q_{i 1}=\left(\frac{\partial C_{p i}}{\partial q_{i}}\right)_{1}=\left(1-g_{m}\right) P_{m 1}-\left(1+f_{m}\right) V_{m}
$$

and therefore:

$$
\beta_{i} q_{i 1}=P_{m 1}\left(p_{m 1}+F_{m 1}\right)
$$

or

$$
q_{1}=P_{m 1}\left(p_{m 1}+F_{m 1}\right) \sum_{i} \beta_{i}^{-1}
$$

and

$$
\left(\sum_{i} \beta_{i}^{-1}\right)^{-1}=\left(p_{m 1}+F_{m 1}\right) \frac{P_{m 1}}{q_{1}}
$$

In similar manner:

$$
\left(\sum_{j} \beta_{j}^{-1}\right)^{-1}=\left(p_{s 1}+F_{s 1}\right) \frac{P_{s 1}}{q_{1}}
$$

The key parameters are thus determined as:

$$
\begin{aligned}
k & =\frac{2 e q_{1}}{P_{s 1}}\left(\left(1-g_{m}\right)\left(p_{s 1}+F_{s 1}\right) \frac{P_{s 1}}{q_{1}}+\left(1+f_{s}\right)\left(p_{m 1}+F_{m 1}\right) \frac{P_{m 1}}{q_{1}}\right) \\
& =2 e\left(\left(1-g_{m}\right)\left(p_{s 1}+F_{s 1}\right)+\left(1+f_{s}\right)\left(p_{m 1}+F_{m 1}\right) \frac{P_{m 1}}{P_{s 1}}\right)
\end{aligned}
$$

from which one may now calculate $\gamma$ or $\Delta P_{s} / \bar{C}, \Delta q / q_{1}$ and $\Delta P_{m} / \bar{C}$, provided one also assigns some value to $\bar{C} / P_{s 1}$. The results are:

$$
\begin{aligned}
\gamma & =\frac{\left(1+f_{s}\right)\left(1+f_{m}\right)}{\left(1+g_{m}\right)\left(1-g_{s}\right)-k}=\frac{\Delta P_{s}}{\bar{C}} \\
\frac{\Delta q}{q_{1}} & =\gamma e \frac{\bar{C}}{P_{s 1}} \text { and } \\
\frac{\Delta P_{m}}{\bar{C}} & =\frac{\left(1+f_{m}\right)\left(p_{s 1}+F_{s 1}\right)+\gamma\left(1-g_{s}\right)\left(p_{m 1}+F_{m 1}\right) P_{m 1} / P_{s 1}}{\left(1-g_{m}\right)\left(p_{s 1}+F_{s 1}\right)+\left(1+f_{s}\right)\left(p_{m 1}+F_{m 1}\right) P_{m 1} / P_{s 1}}
\end{aligned}
$$

\section{Gross Analysis - Conceptual}

Having completed the conceptual analysis for the marginal case, as well as having shown how the parameters in question can be related to operating data, it becomes a shorter task to indicate how the alternative or gross analysis can be carried out.

Whereas in the marginal case the net revenue was regarded to be fine tunable, this view is dropped for the gross decision case in favor of a type of "satisfaction" principle, i.e., for a net revenue which is considered to be adequate and expected. Thus, though the same general expressions are used for $\eta$ and $\Delta \eta$, the details of the supply cost functions are altered as well as the decision rule for the shares bought and sold. 
The supply cost function now need consist only of a fixed and variable (linear) term, as the decision rules that determine production quantities depend only on preconceived profit margins. Thus for manufacturing:

$$
\begin{aligned}
& \pi_{i 1}=p_{m} P_{m 1} q_{i 1}=P_{m 1} q_{i 1}-C_{p i 1}-\left(1+f_{m}\right) V_{m} q_{i 1}-g_{m} P_{m 1} q_{i 1} \\
& \pi_{i 2}=p_{m} P_{m 2} q_{i 2}=P_{m 2} q_{i 2}-C_{p i 2}-\left(1+f_{m}\right)\left(V_{m}+\bar{C}_{m}\right) q_{i 2}-g_{m} P_{m 2} q_{i 2}-\bar{C}_{l} q_{i 2}
\end{aligned}
$$

and for retailing:

$$
\begin{aligned}
& \pi_{j 1}=p_{s} P_{s 1} q_{j 1}=P_{s 1} q_{j 1}-C_{s j 1}-\left(1+f_{s}\right) P_{m 1} q_{j 1}-g_{s} P_{s 1} q_{j 1} \\
& \pi_{j 2}=p_{s} P_{s 2} q_{j 2}=P_{s 2} q_{j 2}-C_{s j 2}-\left(1+f_{s}\right) P_{m 2} q_{j 2}-g_{s} P_{s 2} q_{j 2}
\end{aligned}
$$

Again we let $\bar{C}=\bar{C}_{m}+\bar{C}_{l} /\left(1+f_{m}\right)$ where it should be noted too that the assumption of linearity re $\bar{C}_{l}$ fits naturally into the simpler form of the production cost function.

Noting that each industry's private cost is of the form $(1-p) P q$ and that $\eta$ is the sum of all surplus values:

$$
\begin{aligned}
\eta_{1}= & \left(1+f_{c}\right) \int_{o}^{q_{1}} P d q-f_{c} P_{s 1} q_{1}-\left(1-p_{m}\right) P_{m 1} q_{1}-\left(1-p_{s}\right) P_{s 1} q_{1}+P_{m 1} q_{1}-\bar{C}_{e 1} q_{1} \\
\eta_{2}= & \left(1+f_{c}\right) \int_{o}^{q_{2}} P d q-f_{c} P_{s 2} q_{2}-\left(1-p_{m}\right) P_{m 2} q_{2}-\left(1-p_{s}\right) P_{s 2} q_{2}+P_{m 2} q_{2}-\bar{C}_{e 2} q_{2}-\bar{C}_{r} q_{2} \\
\Delta \eta= & \left(1+f_{c}\right) \int_{q_{1}}^{q_{2}} P d q+p_{m}\left(P_{m 2} q_{2}-P_{m 1} q_{1}\right)-\left(1+f_{c}-p_{s}\right)\left(P_{s 2} q_{2}-P_{s 1} q_{1}\right) \\
& +\left[\bar{C}_{e 1} q_{1}-\left(\bar{C}_{e 2}+\bar{C}_{r}\right) q_{2}\right]
\end{aligned}
$$

Defining $\bar{C}$ and the market factor $M F$ as previously yields:

$$
\begin{aligned}
M F= & \left(1+f_{c}-p_{s}\right) \frac{\Delta P_{s}}{\bar{C}}-p_{s} \frac{\Delta q / q_{1}}{\bar{C} / P_{s 1}} \\
& -p_{m}\left[\frac{P_{m 1}+\Delta P_{m}}{\bar{C}} \cdot \frac{\Delta q}{q_{1}}+\frac{\Delta P_{m}}{\bar{C}}\right]+\left(\frac{1+f_{c}}{2}-p_{s}\right) \frac{\Delta P_{s}}{\bar{C}} \cdot \frac{\Delta q}{q_{1}}
\end{aligned}
$$

Regarding now that:

$$
\begin{aligned}
& C_{p i}=C_{o i}+\alpha_{i} q_{i} \\
& C_{s j}=C_{o j}+\alpha_{j} q_{j}
\end{aligned}
$$

and utilizing the expected net revenue relations:

$$
\begin{aligned}
& q_{i 1}=C_{o i} /\left[\left(1-p_{m}-g_{m}\right) P_{m 1}-\left(1+f_{m}\right) V_{m}-\alpha_{i}\right] \\
& q_{i 2}=C_{o i} /\left[\left(1-p_{m}-g_{m}\right) P_{m 2}-\left(1+f_{m}\right)\left(V_{m}+\bar{C}\right)-\alpha_{i}\right]
\end{aligned}
$$

from which

$$
\Delta q_{i}=\frac{-C_{o i}\left[\left(1-p_{m}-g_{m}\right) \Delta P_{m}-\left(1+f_{m}\right) \bar{C}\right]}{\left[\left(1-p_{m}-g_{m}\right) P_{m 1}-\left(1+f_{m}\right) V_{m}-\alpha_{1}\right]^{2}\left[1+\frac{\left(1-p_{m}-g_{m}\right) \Delta P_{m}-\left(1+f_{m}\right) \bar{C}}{\left(1-p_{m}-g_{m}\right) P_{m 1}-\left(1+f_{m}\right) V_{m}-\alpha_{1}}\right]}
$$


Additionally;

$$
C_{o i}=F_{m 1} P_{m 1} q_{i 1} \quad \text { and } \quad\left(1-p_{m}-q_{m}\right) P_{m 1}-\left(1+f_{m}\right) V_{m}-\alpha_{i}=F_{m 1} P_{m 1}
$$

Therefore:

$$
\Delta q_{m}=-\frac{q_{1}}{F_{m 1} P_{m 1}} \cdot \frac{\left(1-p_{m}-g_{m}\right) \Delta P_{m}-\left(1+f_{m}\right) \bar{C}}{1+\frac{\left(1-p_{m}-g_{m}\right) \Delta P_{m}-\left(1+f_{m}\right) \bar{C}}{F_{m 1} P_{m 1}}}
$$

In like manner for retailing;

$$
\Delta q_{s}=-\frac{q_{1}}{F_{s 1} P_{s 1}} \cdot \frac{\left(1-p_{s}-g_{s}\right) \Delta P_{s}-\left(1+f_{s}\right) \Delta P_{m}}{1+\frac{\left(1-p_{s}-g_{s}\right) \Delta P_{s}-\left(1+f_{s}\right) \Delta P_{m}}{F_{s 1} P_{s 1}}}
$$

The manipulation of these relationships is carried out in appendix $\mathrm{F}$ in a manner similar to that utilized in appendix E, i.e., by equating supply and demand increments. There it is shown that to first order, if

$$
\kappa=e\left[\left(1-p_{m}-g_{m}\right) F_{s 1}+\left(1-p_{s}-g_{s}\right) F_{m 1} \frac{P_{m 1}}{P_{s 1}}\right)
$$

and

$$
\Gamma=\frac{\left(1+f_{m}\right)\left(1+f_{s}\right)}{\left(1-p_{m}-g_{m}\right)\left(1-p_{s}-g_{s}\right)+\kappa}
$$

then

$$
\begin{aligned}
\frac{\Delta P_{s}}{\bar{C}} & =\Gamma \\
\frac{\Delta q}{q_{1}} & =\Gamma e \frac{\bar{C}}{P_{s 1}}
\end{aligned}
$$

and finally:

$$
\frac{\Delta P_{m}}{\bar{C}}=\frac{\left(1+f_{m}\right) F_{s 1}+\Gamma\left(1-p_{s}-g_{s}\right) F_{m 1} P_{m 1} / P_{s 1}}{\left(1-p_{m}-g_{m}\right) F_{s 1}+\left(1+f_{s}\right) F_{m 1} P_{m 1} / P_{s 1}}
$$

from which one also obtains $M F$ via (33).

In the next section the two cases will be numerically evaluated and compared for the upholstered furniture industry.

\section{Numerical Evaluation}

All but three of the parameters invoked in the calculation of MF were obtained directly or indirectly from the two sets of annual reports, $[8,9]$, referred to earlier. The profit fractions, $p_{m}$ and $p_{s}$ as well as the sales commissions, $g_{m}$ and $g_{s}$, were obtained directly from the reports. $f_{m}$ and $f_{s}$ were estimated on the basis of the "current asset turnover rate" and a return on net worth of $\sim$ ten percent per year. The exact choice for these parameters was not critical to the estimate of $M F$. More important were the values chosen for $F_{m 1}, F_{s 1}$, $P_{m 1} / P_{s 1}$, and of course the elasticity, $e$. Whereas $F_{m 1}$ could be obtained directly from the National Association of Furniture Manufacturers (NAFM) report, $F_{s 1}$ was estimated on the assumption of it being twenty percent of the operating costs other than material costs. ${ }^{*}$ The resulting low value $(0.09)$ makes this

* The 20 percent estimate was provided by Mr. George Larsen, Director of Operations Assistance, NHFA, on an informal (non-certified) basis. 
choice less critical than the corresponding value for $F_{m 1} . P_{m 1} / P_{s 1}$ is given directly. in the National Home Furnishings Association (NHFA) report.

Finally, the elasticity value was taken from the 1973 econometric analysis of personal consumption expenditures in the various segments of the United States economy [10]. The value cited is for the industry group SIC 251, "Household Furniture."

In general, the figures represent broader classes of activities than upholstered furniture per se, this being so for both manufacturing and retailing as well as for the price elasticity utilized; however, it is believed that the representation should correspond reasonably well. The NHFA data, for example, exhibit gross margins for the upholstered furniture component which are nearly the same as for the retail store as a whole.

The ratio $\bar{C} / P_{s 1}$ is based on the cost to effect the basic accommodation divided by an average unit price. As was stated earlier $\bar{C}$ includes an estimate for administrative compliance by the manufacturer, assumed by NBS [4] to be $\sim$ ten percent of $\bar{C}$. Except for the estimate of $\Delta q / q_{1}$, this ratio does not enter sensitively into the calculations, i.e., for $M F . \bar{C}$, of course, is directly important to the trade-off comparison being sought, i.e., $q_{1} \bar{C} \cdot M F$ versus $\left[\Delta C_{e}\right]$ as was shown in the text.

Table I displays the set of parametric values chosen. Given there also is an estimate of their uncertainty and the source of the information. These "best" values are used to calculate $\Delta P_{s} / \bar{C}, \Delta P_{m} / \bar{C}, \Delta q / q_{1}$, and $M F$ for the two cases termed "marginal" and "gross," and as displayed in Table II. The estimated range of uncertainty for $M F$ in the gross case is from $\sim 1.4$ to $\sim 1.8$, obtained by varying the parameters cited in a generous way, the largest uncertainty stemming from the uncertainty in $e$.

TABLE I

Manufacturing and Retailing Parametric Ratios

\begin{tabular}{c|c|c|l} 
PARAMETER & $\begin{array}{c}\text { BEST } \\
\text { VALUE }\end{array}$ & UNCERTAINTY & SOURCE \\
\hline e & -0.7 & $\sim 0.3$ & Ref 10 \\
$\mathrm{P}_{\mathrm{m}}$ & 0.03 & $\sim 0.01$ & Ref 8 \\
$\mathrm{f}_{\mathrm{m}}$ & 0.05 & $\sim 0.01$ & Ref 8 \\
$\mathrm{~g}_{\mathrm{m}}$ & 0.05 & $\sim 0.01$ & Ref 8 \\
$\mathrm{p}_{\mathrm{S}}$ & 0.04 & $\sim 0.01$ & Ref 9 \\
$\mathrm{f}_{\mathrm{S}}$ & 0.03 & $\sim 0.01$ & Ref 9 \\
$\mathrm{~g}_{\mathrm{s}}$ & 0.07 & $\sim 0.01$ & Ref 9 \\
$\mathrm{f}_{\mathrm{c}}$ & 0.02 & $\sim 0.01$ & Ref 9, Appendix C \\
$\mathrm{F}_{\mathrm{mI}}$ & 0.23 & $\sim 0.02$ & Ref 8 \\
$\mathrm{~F}_{\mathrm{SI}}$ & 0.09 & $\sim 0.01$ & Ref 9 , G. Larsen \\
$\mathrm{P}_{\mathrm{mI}} / \mathrm{P}_{\mathrm{SI}}$ & 0.57 & $\sim 0.02$ & Ref 9 \\
$\overline{\mathrm{c}} / \mathrm{P}_{\mathrm{SI}}$ & 0.04 & $\sim 0.02$ & Ref 3,4
\end{tabular}

TABLE II

Incremental Market Ratios and Factors

\begin{tabular}{c|c|c}
$\begin{array}{c}\text { MARKET } \\
\text { ENTITY }\end{array}$ & $\begin{array}{c}\text { MARGINAL } \\
\text { CASE }\end{array}$ & $\begin{array}{c}\text { GROSS } \\
\text { CASE }\end{array}$ \\
\hline$\Delta \mathrm{P}_{\mathrm{s}} / \overline{\mathrm{c}}$ & 0.85 & 1.59 \\
$\Delta \mathrm{P}_{\mathrm{m}} / \overline{\mathrm{c}}$ & 0.92 & 1.29 \\
$\Delta \mathrm{q} / \mathrm{q}_{\mathrm{I}}$ & -0.02 & -0.04 \\
$\mathrm{MF}$ & 1.19 & 1.55
\end{tabular}

Some further calculations were undertaken in which it was assumed that the target return was on "net worth" rather than on sales. The results differed in only a negligible way from the ones shown. Accordingly, they have not been reported here.

\section{Conclusion.}

A general approach was outlined which related production and compliance costs of a consumer product safety standard to the damage costs avoided by the standard. The simplest case, namely, the one in which the production maneuver only required more costly input material and a linear increment in labor, and wherein 
also the market system could be regarded as competitive, was considered. These general considerations were than applied to the two-stage industry arrangement of manufacturers and retailers of upholstered furniture. The pre- and post-standard conditions were related through the assumption of constant price elasticity and certain other initial and final industry operating ratios. In this latter category, for example, was the expected profit on sales, and the important consequences arising from the assumed method of decision making by producers, i.e., optimal "fine tuning" or "gross satisfaction" of profit potential.

The principal result of the analysis was the generation of a market factor, $M F$, which when it is multiplied by the incremental unit cost to the manufacturer required to accommodate the standard, yields the unit loss to society arising from the market system. This loss must yet be compared with the avoided damages and regulatory administrative costs in order to determine if a gain in net public benefit is to be realized from imposition of the standard.

In the "gross decision" model, which avoids the assumption of fine-tuned optimization on the part of the producer, the value of $M F$ obtained for the upholstered furniture case was $\$ 1.5 \pm 0.3$, whereas in the "fine tuned" model, the value of $M F$ obtained was $\sim 1.2 \pm 0.1$. From these considerations a "best" value of $\simeq 1.5$ (favoring the gross decision model more) was then incorporated into other studies by NBS to complete an analysis of the costs and benefits of the proposed standard.

\section{Epilogue}

Although the reader must refer to the cited NBS report [4] if he is to learn the full details concerning the exact manner in which the results of this paper were utilized, it is of interest here to indicate an approximate final result regarding the expected gain in net public benefit.

Two different possible accommodations on the part of production were considered. In the first the use of aluminum barriers along with a boric acid base treatment of the cotton batting was postulated. [3] For this system $\bar{C}$ varied between $\sim \$ 7$ and $\$ 4$ per unit depending upon the postulated distribution of fabric types. In these figures a unit stands for an "average" of chairs and sofas. In the second a less expensive but more hypothetical accommodation was postulated which utilized a fabric backing of latex containing encapsulated sulphur. For this system $\bar{C} \simeq \$ 2$ per unit.

Taking into account certain improvement trends already underway in the industry, and making allowance for fire loss avoidance due to the parallel introduction of smoke detectors, the fire loss avoidance which could be credited to the upholstered furniture standard was estimated to be $\sim \$ 11$ per unit. The actual yearly avoidance loss was estimated to be $\sim \$ 1.1$ per unit.* This figure when integrated and discounted (at the rate of 7 percent, see appendix C) per year over a period of 17 years (the estimated average lifetime of the furniture) yielded the savings of $\$ 11$ per unit cited above.

At a mean retail price, $P_{s 1}$, of $\sim \$ 140$ per unit $\bar{C} / P_{s 1}$ takes the value of 0.03 to 0.05 for the barrier accommodation and $\sim 0.015$ for the sulphur accommodation. Using a market factor of $\sim 1.5$ yields societal costs for accommodating the standard which range from $\sim \$ 3$ to $\sim \$ 10$ per unit. Since these values when compared with the avoided cost of $\$ 11$ per unit break even or show a gain in net benefit, it would appear that the standard constitutes a likely cost effective maneuver. It is therefore worthy of further consideration by the Consumer Product Safety Commission (CPSC).

The author wishes to acknowledge the excellent review and criticism received of this paper from Dr. Charles R. Johnson of the Department of Economics and the Institute for Physical Science and Technology of the University of Maryland and of the Center for Applied Mathematics of the National Bureau of Standards.

\section{References}

[1] Consumer Product Safety Act, 92-573, Section 9(c), p. 10.

[2] Study of the Economic Impact of a Proposed Cigarette Ignition Standard for Upholstered Furniture-Commentary on Possible Economic Impacts, Report to CPSC, CPSC-C-74-195 Task 9922; P. R. Beck, W. E. Riddle, T. A. McClure, J. L. Lindholm; Battelle (Columbus); April 1975.

[3] Private NBS Memorandum, J. H. Winger, February 24, 1976.

[4] Preliminary Report on Evaluating Alternatives for Reducing Upholstered Furniture Fire Losses, B. Buchbinder, S. G. Helzer, F. L. Offensend; NBSIR 77-1381, November 1977; NTIS.

* Includes an estimate for the so-called value-of-life, a concept called into question in Reference 5. 
Decision Analysis of Strategies for Reducing Upholstered Furniture Fire Losses, F. L. Offensend, S. G. Helzer, B. Buchbinder; NBS; 1978 in process, final report.

[5] Costs, Real and Perceived Examined in a Risk-Benefit Framework, C. O. Muehlhause in "Environmental Damage Costs", OECD (Paris); 1974.

[6] Cost-Benefit Analysis, Chapter 23; E. J. Misham; Praeger, 1971.

[7] Considerations in the Use of Sampling Plans with Mandatory Safety Standards, V. L. Broussalian, A. J. Farrar, J. W. Lyons, C. O. Muehlhause (Chairman), M. G. Natrella, J. R. Rosenblatt, R. D. Stiehler, J. H. Winger; NBSIR 75-697; June 1975; NTIS.

[8] 1976: Furniture Manufacturers Comparative Operating Ratios for 1975, M. S. Sherman, M. J. Reddan; NAFM; 9401 Connecticut Avenue, Suite 911, Washington, D.C. 20015.

[9] 1976: Reports on NHFA Member Stores Operating Experiences for 1975, NHFA; 405 Merchandise Mart, Chicago, Illinois 60654. [10] 1985: Industry Forecasts of the American Economy, Chapter 2; Table 2-2; C. Almon, Jr., M. B. Buckler, L. M. Horwitz, T. C. Reimbold; Heath and Company; Lexington, Massachusetts, 1974.

\section{Appendix A. Misperceived Risk as an Externality}

The net public benefit, $\eta$, can be optimized subject to the demand constraint by the method of "Lagrange Multipliers":

$$
\begin{gathered}
\Phi=\int_{\infty}^{P_{m}+V_{r^{\prime}}}\left(V_{p}-\bar{V}_{r}\right) \frac{d q}{d V_{p}} d V_{p}-C_{p}\left(q_{m}, \omega\right)+\lambda\left[q_{m}-\int_{\infty}^{P_{m}+V_{r^{\prime}}} \frac{d q}{d V_{p}} d V_{p}\right] \\
\frac{\partial \Phi}{\partial P_{m}}=\left(P_{m}+\bar{V}_{r}^{\prime}-\bar{V}_{r}\right)\left(\frac{d q}{d V_{p}}\right)_{P_{m}+V_{r^{\prime}}} \cdot 1-\lambda\left(\frac{d q}{d V_{p}}\right)_{P_{m}+V_{r^{\prime}}}=0 \\
\therefore \lambda=P_{m}+\bar{V}_{r}^{\prime}-\bar{V}_{r} \\
\frac{\partial \Phi}{\partial q_{m}}=-\frac{\partial C_{p}}{\partial q_{m}}+\lambda=0 \\
\therefore \frac{\partial C_{p}}{\partial q_{m}}+\left(\bar{V}_{r}-\bar{V}_{r}^{\prime}\right)=P_{m} \\
\frac{\partial \Phi}{\partial \omega}=\int_{\infty}^{P_{m}+V_{r}}-\frac{\partial V_{r}}{\partial \omega} \cdot \frac{d q}{d V_{p}} d V_{p}+\left(P_{m}+\bar{V}_{r}-\bar{V}_{r}{ }^{\prime}\right)\left(\frac{d q}{d V_{p}}\right)_{\omega} \cdot \frac{d \bar{V}_{r}^{\prime}}{d \omega}-\frac{\partial C_{p}}{\partial \omega}-\lambda\left(\frac{d q}{d V_{p}}\right) \cdot \frac{d \bar{V}_{r}^{\prime}}{d \omega}=0 \\
\therefore \frac{\partial C_{p}}{\partial \omega}+q_{m} \frac{\partial \bar{V}_{r}}{\partial \omega}=0
\end{gathered}
$$

which conditions were exhibited in the text.

\section{Appendix B. Optimizing Private Net Revenue}

That private net revenue is optimized by optimizing a net benefit expression which includes only cost terms contained within the market system can be shown using the method of "Lagrange multipliers."

$$
\begin{gathered}
\Phi=\int_{\infty}^{P_{m}} V_{P} \frac{d q}{d V_{p}} \cdot d V_{p}-\sum_{i} C_{p i}\left(q_{i}, \omega_{i}\right)-\sum_{i} q_{i} \bar{C}_{l}\left(\omega_{i}\right)+\lambda\left[\sum_{i} q_{i}-\int_{\infty}^{P_{m}} \frac{d q}{d V_{p}} \cdot d V_{p}\right] \\
\frac{\partial \Phi}{\partial P_{m}}=-P_{m}\left(\frac{d q}{d V_{P}}\right)_{P_{m}}+\lambda\left(\frac{d q}{d V_{P}}\right)_{P_{m}}=0 \\
\therefore \lambda=P_{m}
\end{gathered}
$$




$$
\begin{gathered}
\frac{\partial \Phi}{\partial q_{i}}=-\frac{\partial C p_{i}}{\partial q_{i}}-\bar{C}_{l}\left(\omega_{i}\right)+\lambda \\
\therefore \frac{\partial C p_{i}}{\partial q_{i}}+\bar{C}_{l}\left(\omega_{i}\right)=P_{m} \\
\frac{\partial \Phi}{\partial \omega_{i}}=-\frac{\partial C p_{i}}{\partial \omega_{i}}-q_{i} \frac{\partial \bar{C}_{l}}{\partial \omega_{i}}=0 \\
\therefore \frac{\partial C p_{i}}{\partial \omega_{i}}+q_{i} \frac{\partial \bar{C}_{l}}{\partial \omega_{i}}=0
\end{gathered}
$$

which conditions were stated in the text to be optimal for the set of competing firms.

\section{Appendix C. Effect of Credit Buying}

In the purchase of durable goods, credit buying, i.e., buying on time, is of common practice. In the case of home furniture, for example, approximately 70 percent [9] of the purchases are financed this way. Typically $\sim 15$ percent is paid down and the remainder is either "front loaded" at $\sim 10$ percent per year, or the payments are made monthly at $\sim 1$ and $1 / 2$ percent per month on the balance, the term of the contract usually being one year. There are thus two categories of buyers, "cash" and "credit."

These two consumer groups presumably operate under different budget constraints and would exhibit (if the data were available) different elasticities. In addition, credit buyers must find it preferable to pay a higher present value for the product in order to obtain it immediately, than to save (at a lower interest rate than he must pay for credit) for some future purchase.

Though these two groups are non-identical and some other complexities prevail, it will be assumed that it is possible to homogenize them nevertheless, i.e., to represent them by a joint demand function. Assume too that the seller charges at an interest rate $j$ commensurate with a rate of return on his investments. The present value, $P_{v s}$, paid to him is thus:

$$
P_{v s}=P_{0}+\frac{\left(P_{s}-P_{0}\right)(1+j)}{1+j}=P_{s}
$$

whereas the present value to the consumer paid by him is given by:

$$
P_{v c}=P_{0}+\left(P_{s}-P_{0}\right)(1+j) /(1+i) \simeq P_{s}+(j-i)\left(P_{s}-P_{0}\right)>P_{s}
$$

where $P_{0}$ is the amount of the retail price paid down, and $i$ is the interest rate $(i<j)$ available to consumers on investment.

For cash buyers evidently $P_{v c}=P_{s}$. Accordingly, homogenization of these two groups would lead to:

$$
P_{v}=p_{c} P_{s}+\left(1-p_{c}\right)\left[P_{s}+(j-i)\left(P_{s}-P_{0}\right)\right]=P_{s}+\left(1-p_{c}\right)(j-i)\left(P_{s}-P_{0}\right)
$$

as the present value paid for the product, where $p_{c}$ is the fraction of consumers who are cash buyers. Let this be designated:

$$
P_{v}=\left(1+f_{c}\right) P_{s}
$$

where apparently:

$$
f_{c}=\left(1-p_{c}\right)(j-i)\left(1-P_{0} / P_{s}\right)
$$

Thus for home furniture, typically

$$
\left.f_{c} \simeq 0.7(0.10-0.07)(1-0.15) \simeq 0.02 \text { (as given in Table } 1\right)
$$


We may thus regard that:

$$
\begin{aligned}
\eta_{1} & =\int_{\infty}^{\left(1+f_{c}\right) P_{1}} P d q-\left(1+f_{c}\right) P_{1} q_{1}+P_{1} q_{1}-\sum_{i 1} C_{p i}\left(q_{i}\right) \cdots \\
\eta_{2} & =\int_{\infty}^{\left(1+f_{c}\right) P_{2}} P d q-\left(1+f_{c}\right) P_{2} q_{2}+P_{2} q_{2}-\sum_{i 2} C_{p i}\left(q_{i}\right) \cdots \\
\Delta \eta & =\int_{\left(1+f_{c}\right) P_{1}}^{\left(1+f_{c}\right) P_{2}} P d q-f_{c}\left(P_{2} q_{2}-P_{1} q_{1}\right)-\sum_{i 2} C_{p i}\left(q_{i}\right)-\sum_{i 1} C_{p i}\left(q_{i}\right) \cdots \\
& =\left(1+f_{c}\right)\left[P_{1}+\frac{\Delta P}{2}\right] \Delta q-f_{c}\left(P_{2} q_{2}-P_{1} q_{1}\right)-\left(\sum_{i 2} C_{p i}\left(q_{i}\right)-\sum_{i} C_{p i}\left(q_{i}\right)\right) \ldots
\end{aligned}
$$

which is to say that:

a) the benefits are increased by the factor: $1+f_{c}$, and

b) an exchange term $-f_{c}\left(P_{2} q_{2}-P_{1} q_{1}\right)$ remains in the net benefit expression, arising from the fact that the time value of money for consumer and retailer are not the same.

\section{Appendix D. Change in Benefit}

The change in consumer benefit resulting from a change in price and volume of sales is given by:

$$
\int_{q_{1}}^{q_{2}} P d q
$$

which integral may be readily evaluated on the assumption of constant price elasticity over the range from $q_{1}$ to $q_{2}$. That is:

$$
q=q_{1}\left(\frac{P}{P_{1}}\right)^{e}
$$

Therefore:

$$
\begin{aligned}
\int_{q_{1}}^{q_{2}} P d q & =\int_{P_{1}}^{P_{2}} P \cdot e q_{1}\left(\frac{P}{P_{1}}\right)^{e-1} \frac{d P}{P_{1}}=e q_{1} P_{1} \int_{P_{1}}^{P_{2}}\left(\frac{P}{P_{1}}\right)^{e} \frac{d P}{P_{1}} \\
& =\left.\frac{e q_{1} P_{1}}{1+e} \cdot\left(\frac{P}{P_{1}}\right)^{1+e}\right|_{P_{1}} ^{P_{2}}=\frac{e q_{1} P_{1}}{1+e}\left\{\left(\frac{P_{2}}{P_{1}}\right)^{1+e}-1\right\} \\
& =\frac{e q_{1} P_{1}}{1+e}\left\{\left(1+\frac{\Delta P}{P_{1}}\right)^{1+e}-1\right\} \\
& \simeq \frac{e q_{1} P_{1}}{1+e}\left\{(1+e) \frac{\Delta P}{P_{1}}+\frac{(1+e) e}{2} \cdot\left(\frac{\Delta P}{P_{1}}\right)^{2}\right\} \\
& \simeq e q_{1} \Delta P\left\{1+\frac{e}{2}\left(\frac{\Delta P}{P_{1}}\right)\right\}
\end{aligned}
$$

But also:

$$
q_{2}=q_{1}\left(\frac{P_{2}}{P_{1}}\right)^{e} \quad \Delta q=q_{1}\left\{\left(\frac{P_{2}}{P_{1}}\right)^{e}-1\right\}
$$




$$
\begin{gathered}
\Delta q=e q_{1} \frac{\Delta P}{P_{1}}\left\{1+\frac{e-1}{2}\left(\frac{\Delta P}{P_{1}}\right)\right\} \\
\therefore e q_{1} \Delta P=P_{1} \Delta q-\frac{e(e-1)}{2} q_{1} P_{1}\left(\frac{\Delta P}{P_{1}}\right)^{2} \\
\int_{q_{1}}^{q_{2}} P d q=P_{1} \Delta q+\frac{e}{2} \Delta P \Delta q\left[1-(e-1) \frac{q_{1}}{P_{1}} \frac{\Delta P}{\Delta q}\right]=P_{1} \Delta q+\frac{1}{2}[\Delta P \Delta q
\end{gathered}
$$

to second order.

\section{Appendix $\mathbf{E}$. Evaluation of $\Delta \mathbf{P}_{\mathbf{s}}, \Delta \mathbf{P}_{\mathbf{m}}$, and $\Delta \mathbf{q}-$ Marginal Case}

From the text $\Delta P_{s}$ and $\Delta P_{m}$ are related via the equality of $\Delta q_{s}$ and $\Delta q_{m}$.

$$
\begin{aligned}
{\left[\left(1-g_{m}\right) \Delta P_{m}-\left(1+f_{m}\right) \bar{C}\right] \sum_{i} \beta_{i}^{-1}=\left[\left(1-g_{s}\right) \Delta P_{s}-\left(1+f_{s}\right) \Delta P_{m}\right] \sum_{j} \beta_{j}^{-1} } \\
\Delta P_{m}=\frac{\left(1+f_{m}\right) \bar{C} \sum_{i} \beta_{i}^{-1}+\left(1-g_{s}\right) \Delta P_{s} \sum_{j} \beta_{j}^{-1}}{\left(1-g_{m}\right) \sum_{i} \beta_{i}^{-1}+\left(1+f_{s}\right) \sum_{j} \beta_{j}^{-1}} \\
\Delta q=\frac{1}{2} \sum_{i} \beta_{i}^{-1}\left\{\left(1-g_{m}\right) \frac{\left(1+f_{m}\right) \bar{C} \sum_{i} \beta_{i}^{-1}+\left(1-g_{s}\right) \Delta P_{s} \sum_{j} \beta_{j}^{-1}}{\left(1-g_{m}\right) \sum_{i} \beta_{i}^{-1}+\left(1+f_{s}\right) \sum_{j} \beta_{j}^{-1}}-\left(1+f_{m}\right) \bar{C}\right\} \\
=\frac{1}{2} \frac{\left(1-g_{m}\right)\left(1-g_{s}\right) \Delta P_{s}-\left(1+f_{m}\right)\left(1+f_{s}\right) \bar{C}}{\left(1-g_{m}\right)\left(\sum_{j} \beta_{j}^{-1}\right)^{-1}+\left(1+f_{s}\right)\left(\sum_{i} \beta_{i}^{-1}\right)^{-1}}
\end{aligned}
$$

which to first order also $=e q_{1} \frac{\Delta P_{s}}{P_{s 1}}(c f$. appendix D).

From this one obtains:

$$
\Delta P_{s}=\frac{\left(1+f_{s}\right)\left(1+f_{m}\right) \bar{C}}{\left(1-g_{m}\right)\left(1-g_{s}\right)-k}
$$

where

$$
k=\frac{2 e q_{1}}{P_{s 1}}\left[\left(1-g_{m}\right)\left(\sum_{j} \beta_{j}^{-1}\right)^{-1}+\left(1+f_{s}\right)\left(\sum_{i} \beta_{i}^{-1}\right)^{-1}\right]
$$

Also for convenience let:

$$
\gamma=\frac{\left(1+f_{s}\right)\left(1+f_{m}\right)}{\left(1-g_{m}\right)\left(1-g_{s}\right)-k}
$$

Then:

$$
\Delta P_{s}=\gamma \bar{C} \quad \text { and } \quad \Delta q=\gamma e q_{1} \frac{\bar{C}}{P_{s 1}}
$$


and finally:

$$
\Delta P_{m}=\frac{\left(1+f_{m}\right)\left(\sum_{j} \beta_{j}^{-1}\right)^{-1}+\left(1-g_{s}\right)\left(\sum_{i} \beta_{i}^{-1}\right)^{-1} \gamma}{\left(1-g_{m}\right)\left(\sum_{j} \beta_{j}^{-1}\right)^{-1}+\left(1+f_{s}\right)\left(\sum_{i} \beta_{i}^{-1}\right)^{-1}} \bar{C}
$$

19. Appendix F. Evaluation of $\Delta \mathbf{P}_{\mathrm{s}}, \Delta \mathbf{P}_{\mathrm{m}}$, and $\Delta \mathrm{q}-\mathbf{G r o s s}$ Case

$$
-\frac{\Delta q}{q_{1}}=\frac{a_{m} \Delta P_{m}-b_{m} \bar{C}}{1+a_{m} \Delta P_{m}-b_{m} C}=\frac{a_{s} \Delta P_{s}-b_{s} \Delta P_{m}}{1+a_{s} \Delta P_{s}-b_{s} \Delta P_{m}}
$$

where:

$$
\begin{array}{ll}
a_{m}=\frac{1-p_{m}-g_{m}}{F_{m 1} P_{m 1}} & b_{m}=\frac{1+f_{m}}{F_{m 1} P_{m 1}} \\
a_{s}=\frac{1-p_{s}-g_{s}}{F_{s 1} P_{s 1}} & b_{s}=\frac{\left(1+f_{s}\right)}{F_{s 1} P_{s 1}}
\end{array}
$$

from which

$$
\Delta P_{m}=\frac{a_{s} \Delta P_{s}+b_{m} \bar{C}}{a_{m}+b_{s}}
$$

and

$$
\frac{-\Delta q / q_{1}}{1+\Delta q / q_{1}}=\frac{a_{m} a_{s}}{a_{m}+b_{s}} \Delta P_{s}-\frac{b_{m} b_{s}}{a_{m}+b_{s}} \bar{C}
$$

From Appendix D:

$$
\frac{\Delta q}{q_{1}}=e \frac{\Delta P_{s}}{P_{s 1}}\left(1+\frac{e-1}{2} \frac{\Delta P_{s}}{P_{s 1}}\right)
$$

or, to first order only

$$
\frac{\Delta P_{s}}{C}=\frac{b_{m} b_{s} / a_{m} a_{s}}{1+\frac{e}{P_{s 1}} \cdot \frac{a_{m}+b_{s}}{a_{m} a_{s}}}
$$

which reduces to:

$$
\frac{\Delta P_{s}}{\bar{C}}=\frac{\left(1+f_{m}\right)\left(1+f_{s}\right)}{\left(1-p_{m}-g_{m}\right)\left(1-p_{s}-g_{s}\right)+e\left[\left(1-p_{m}-g_{m}\right) F_{s 1}+\left(1+f_{s}\right) F_{m 1} \frac{P_{m 1}}{P_{s 1}}\right]}
$$

By analogy to the marginal case this may be written as:

$$
\frac{\Delta P_{s}}{C}=\Gamma=\frac{\left(1+f_{m}\right)\left(1+f_{s}\right)}{\left(1-p_{m}-g_{m}\right)\left(1-p_{s}-g_{s}\right)+\kappa}
$$


where:

$$
\kappa=e\left[\left(1-p_{m}-g_{m}\right) F_{s 1}+\left(1-p_{s}-g_{s}\right) F_{m 1} \frac{P_{m 1}}{P_{s 1}}\right.
$$

Note however, $\kappa$ appears in $\Gamma$ with a positive sign whereas in $\gamma$ the term $k$ appeared with a negative sign.

Thus, also to first order:

$$
\frac{\Delta q}{q_{1}}=e \frac{\Delta P_{s}}{P_{s 1}}=\Gamma e \frac{\bar{C}}{P_{s 1}}
$$

Finally:

$$
\frac{\Delta P_{m}}{\bar{C}}=\frac{\Gamma a_{s}+b_{m}}{a_{m}+b_{s}}=\frac{\left(1+f_{m}\right) F_{s 1}+\Gamma\left(1-p_{s}-g_{s}\right) F_{m 1} \frac{P_{m 1}}{P_{s 1}}}{\left(1-p_{m}-g_{m}\right) F_{s 1}+\left(1+f_{s}\right) F_{m 1} \frac{P_{m 1}}{P_{s 1}}}
$$

